Irq $\mathrm{J}$ Pharm

Vol. ${ }^{9} \&$ '·, No. ' , r. $1 \cdot$

\title{
Prevalence of knee arthritis and role of synovial fluid aspiration in its improvement among patients with musculoskeletal brucellosis in Erbil
}

\author{
Khalid A.O AL- Dabbagh \\ Department of Medicine, College of Medicine \\ Hawler Medical University, Iraq
}

\begin{tabular}{ll} 
Received: & Accepted \\
\hline r. $1 \cdot . r \ldots 1$ & 10.4 .4 .99
\end{tabular}

\begin{abstract}
The study was conducted to record the prevalence and necessity regarding joint aspiration among patients with brucella knee arthritis and its role in the process of improvement. This study was a prospective analysis of 10 . patients with musculoskeletal brucellosis (M-S brucellosis) recorded in the period from May $r \ldots$. -July $r \ldots \wedge$ ( $r q$ months) in Erbil governorate, which cavers population of more than one million. Out of 10 . cases; $r$. patients who developed knee arthritis ( $r . \%)$ subjected to a comparative study and analysis to determine its prevalence and characters and the role of synovial fluid aspiration in the improvement. Out of the thirty; $1 \wedge$ patients ( $~ \% \%$ ) were females and $1 r$ patients $(\xi \cdot \%)$ males, the age group between $r \cdot-\varepsilon \cdot$ years. All patients met the criteria of the diagnosis and all patients were received anti -brucella antibiotic, 10 patients subjected to aspiration of the fluid and they were compared with reminders who were not subjected to fluid aspiration.

$\mathrm{P}$ value was not significant in both aspirated \& non aspirated group after 7 th, $\wedge$ th, $1 \cdot$ th and the end of the twelve weeks. In conclusion, M-S brucellosis is common in Erbil. Brucella knee arthritis represents about $r . \%$ of musculoskeletal manifestation of Brucellosis. Serial joint aspirations of synovial fluid did not play any role in the improvement of patients. Aspiration of synovial fluid may help in the diagnosis rather than a step for treatment.
\end{abstract}

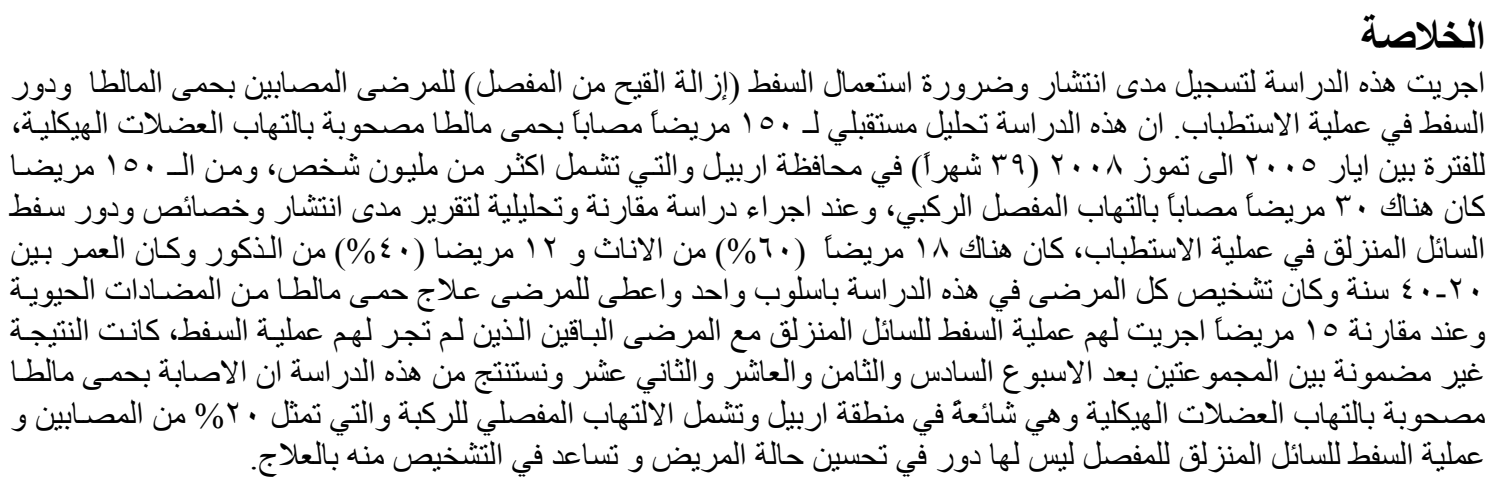

B rucella is small, aerobic, non-motile, gram-negative coccobacilli which grow well at $r^{\circ} \mathrm{C}$ in any high quality peptone-based medium enriched with blood or serum.
Brucellosis is worldwide in distribution and is endemic in certain areas such as Mediterranean countries.

Only four of the six recognized species of brucella, are known to be human pathogens; Brucella melitensis the most virulent ,causes disease in goats, sheep, and camels, B.abortus in cattle 
which is the only species responsible for human infection in UK. B.suis in pigs which is responsible for the disease in US, and B.canis in dogs.

Infection of the joint is the most frequent localized complication of brucellosis, and a common cause of infectious arthritis in the countries where the disease is endemic.

Humans acquire brucellosis mostly by ingesting contaminated milk or dairy products or contracted from infected animals. Brucellosis typically presents as a febrile illness with hepatosplenomegaly, lymphadenopathy, and leucopenia or pancytopenia.

Five musculoskeletal manifestations may occur in brucellosis: sacroiliitis, peripheral arthritis, spondylitis, osteomyelitis and bursitis. Peripheral arthritis affecting the hip, knee or elbow is the most common pattern of joint involvement.

Osteoarticular brucellosis occurs in one-third of patients, especially those infected with B. melitensis. ${ }^{r}$

Unlike septic arthritis caused by other microorganisms, septic arthritis due to brucellosis can be suspected if it is associated with normal white blood cell count and normal or slightly elevated erythrocyte sedimentation rate.

Radiological appearances of the joint are not characteristic in brucellosis and appear normal in most of the cases or show non-specific changes.

Detection of serum brucella agglutinins is essential for diagnosis where as blood cultures may have variable positivity. Blood cultures are positive only in $r \cdot-v . \%$ of patients with brucella arthritis.

One possible reason for the somewhat different clinical features of

Brucella arthritis may be that some of the cases actually represent a reactive type of arthritis and not direct invasion by the pathogen.

Molecular techniques were first applied for the diagnosis of brucellosis in 1919 and application of PCR (polymerase chain reaction) in the diagnosis of human brucellosis has been used recently. ${ }^{\mathrm{V}}$

Synovial fluid is inflammatory with protein greater than $r \mathrm{~g} / \mathrm{dl}$; white cell count is below $1 \ldots$ cells $/ \mathrm{ml}$ with predominance of lymphomononuclear cells. ${ }^{\lambda}$

Treatment for at least 7 weeks with two drugs seems warranted to improve outcome and prevent relapses.
The standard treatment of uncomplicated cases in adults and children $\wedge$ years of age and older is $1 \ldots$ mg doxycycline twice a day for 7 weeks plus I gm streptomycin daily for $r$ to $r$ weeks, rifampicin can be used as a substitute for streptomycin in a dose of ฯ..-9.. mg for 7 weeks.

Combination regimes of two or three drugs are more effective for complicated cases like musculoskeletal involvement; for example

1. Doxycycline plus rifampin or streptomycin (or both), or

$r$. Ttrimethoprim-sulfa methoxazole plus rifampin or Streptomycin (or both) is effective in doses as follows:

Doxycycline $1 . .-r \ldots \mathrm{mg} / \mathrm{d}$ in divided doses.

Trimethoprim rr. mg/d, plus sulfamethoxazole $17 . . \mathrm{mg} / \mathrm{d}$, in divided doses.

Rifampin $\uparrow \ldots-1\} \ldots \mathrm{mg} / \mathrm{d}$.

Streptomycin $1 \ldots \mathrm{mg}$ intramuscularly once a day.

Longer courses of therapy (e.g. several months) may be required to cure relapses or if complicated with arthritis, spondylitis, sacroilitis, osteomyelitis or meningitis. Saltoglu et al. ${ }^{(\cdot)}$ concluded that a $\leqslant 0$-day course of doxycycline plus ofloxacin combination was as effective as doxycycline plus rifampin combination in patients with brucellosis.

The study was conducted to record the prevalence, characters and necessity regarding joint aspiration among patients with brucella knee arthritis and its role in the process of improvement.

\section{Patients and Methods}

This study was a prospective analysis of 10. patients with Musculoskeletal brucellosis recorded in the period from May $r \ldots \circ$ to July $r \ldots \wedge$ ( $r q$ months) in Erbil governorate, which usurers a population of more than one million. Out of 10 . cases; $r$. patients who developed knee arthritis $(r \cdot \%)$ subjected to a comparative study and analyzed to determine its prevalence and characters and the role of synovial fluid aspiration in its improvement.

Knee brucellosis was diagnosed on the basis of the following criteria; Knee arthritis, supported by the detection of specific antibodies at significant titers and/or demonstration of at least fourfold rise in the antibody titer in serum specimen taken over $r$ or $r$ weeks. 
Significant titers were determined to be >1/17. in the standard tube agglutination test (SAT)." With positive result of $r$-Mercapto Ethanol.

Complete history and physical examination of all patients were done.

Each patient was examined fully to detect knee arthritis (Arthritis considered in this study; swelling, effusion, decreased in range of motion or tenderness).'

Swelling however, and effusion, and positive patellar tape encountered in all cases were considered essential for the study.

A complete blood count and erythrocyte sedimentation rate (ESR), the standard tube agglutination test (SAT), rMercapto ethanol were performed in all patients.

The patients were classified into two groups (group A aspirated and group $B$ non aspirated). Aspiration of synovial fluid were done for 10 patients only. Both groups received Triple antibrucella therapy consist of Streptomycin Igm intramuscular injection for 10 days + rifampicin $r . . \mathrm{mg}$ twice daily +Doxycycline 1.. mg twice daily for six to $1 r$ weeks.

Criteria of improvement were:

1- Disappearance of symptoms.

$r$ - Complete remission of arthritis.

$r$ - Negative $r$-Mercapto ethanol result.. Data were entered into a computer using the EPI 7 computer program. Fisher exact test was used when ever applicable. $P$ value of equal or less than. .0 was considered as statistically significant.

\section{Results}

Of the 10. patients with osteoarticular brucellosis, $r$. patients $(r . \%)$ had knee brucellosis (Figure '). From the $r$. patients with brucella knee arthritis, eighteen patients $(\% . \%)$ were females and ir patients $(\varepsilon \cdot \%)$ males, with female to male Ratio was (1.0:1).

Right side arthritis was observed in $1 \wedge$ ( 7 . $\%)$ patients and left side involvement in 1 . ( $r$ \% $)$ patients, while $r$ patients presented with bilateral involvement (Table 1).

Table $r$ shows brucella agglutination test done for the studied patients. All patients had significant brucella agglutination test (BAT); Is patients gets the titer $1 / 1 \% \cdot$, . Twelve patients had a titer of $1 / \pi r$. and four had titer of $1 / \pi \varepsilon$.

This study shows that at least ir weeks of treatment is required for the recovery
(Table $r$ ), and there are no significant differences between the aspirated and non aspirated groups, (table $\leqslant$ a, b, \& c shows that $P$ values were not significant).

Most of the patients had normal WBCs count \& normal or mild elevated ESR, (Table ${ }^{\circ}$ )

\section{Discussion}

This study shows that females are affected more than males, Brucellosis can occur at any age but in this study the most common age groups involved were adult and middle aged and this finding goes with other studies.

Peripheral arthritis, which
presented as monoarthritis, is predominantly affected large joints, such as the knees, hips and ankles. In this study, peripheral arthritis especially knee is the most frequent type of musculoskeletal involvement in brucellosis $(r . \%)$, and it is higher than the rate given by other studies.',

The right knee joint $(7 . \%)$ was found to be affected more than the left (rr\%).

This study showed that $7.77 \%$ of cases are bilateral (pauciarticular), while १ч.rт\% were unilateral monoarthritis, similar to other study."

This study shows that none of the patients has leucopenia and (YT.T7\%) have leucocytosis while (Vr. $r$ r\%) were normal. Leucopenia is not the rule in brucellosis and the total WBCs count is usually normal. ${ }^{1 v}$ The changes in ESR 


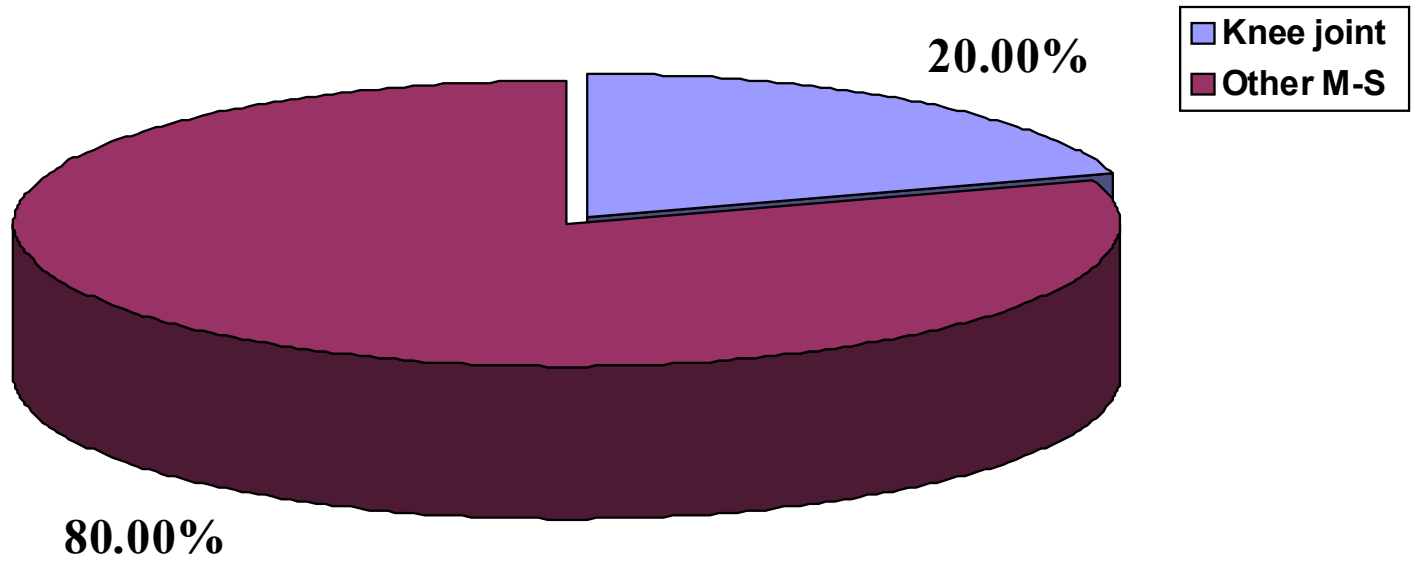

Figure 1: Prevalence of knee brucellosis in $10 \cdot$ patients with M-S brucellosis

Table I: Side of knee joint involvement

\begin{tabular}{|c|c|c|}
\hline Pattern & No. & $\%$ \\
\hline Right & 11 & 7. \\
\hline Left & $1 \cdot$ & $r r . r r$ \\
\hline Bilateral & $r$ & $7.7 \tau$ \\
\hline Total & $r \cdot$ & $1 \cdots$ \\
\hline
\end{tabular}


Table ${ }^{r}$ : Distribution of patient's results by brucella agglutination test

\begin{tabular}{|c|c|c|}
\hline Titer & No. & $\%$ \\
\hline $1 / 17$. & $1 \varepsilon$ & $\{7.7$ \\
\hline $1 / Y \mu$. & IT & $\varepsilon$ \\
\hline $1 / 7 \varepsilon$ & $\xi$ & $1 \pi . r$ \\
\hline Total & $r$. & $1 \ldots$ \\
\hline
\end{tabular}

Table r: Period needed for improvement

\begin{tabular}{|c|c|c|c|c|}
\hline & \multicolumn{2}{|c|}{ Aspirated group } & \multicolumn{2}{|c|}{ Non Aspirated group } \\
\hline Weeks & No. & $\%$ & No. & $\%$ \\
\hline $7 \mathrm{Wks}$ & 1 & 7.77 & $r$ & חז.r. \\
\hline ^Wks & IT & $\Lambda$. & 1. & 77,7 \\
\hline $1 \cdot \mathrm{Wks}$ & $r$ & מת.זו & r & سח.rו \\
\hline I rWks & . & . & 1 & 7.77 \\
\hline Total & 10 & $1 \ldots$ & 10 & $1 \ldots$ \\
\hline
\end{tabular}


Irq J Pharm

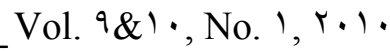

Table s: proportion of improvement of the two groups by time a - after 1 weeks

\begin{tabular}{|c|c|c|c|c|}
\hline & \multicolumn{2}{|c|}{ Group A } & \multicolumn{2}{|c|}{ Group B } \\
\hline Improvement & No. & $\%$ & No. & $\%$ \\
\hline$+\mathrm{Ve}$ & 1 & 7.77 & Y & תז.Tו \\
\hline$-\mathrm{Ve}$ & $1 \leq$ & qT.Tr & $1 \pi$ & 17.77 \\
\hline Total & 10 & $1 \ldots$ & 10 & $1 \ldots$ \\
\hline
\end{tabular}

$\mathrm{P}=1$ by Fisher exact test

b- Show improvement after $\wedge$ weeks

\begin{tabular}{|c|c|c|c|c|}
\hline & \multicolumn{2}{|c|}{ Group A } & \multicolumn{2}{|c|}{ Group B } \\
\hline Improvement & No. & $\%$ & No. & $\%$ \\
\hline$+\mathrm{Ve}$ & $1 r$ & 1..77 & Ir & $\Lambda$. \\
\hline$-\mathrm{Ve}$ & $r$ & TrTIT & $r$ & $r$. \\
\hline Total & 10 & $1 \ldots$ & 10 & $1 \ldots$ \\
\hline
\end{tabular}

$P=1$ by Fisher exact test 
Irq J Pharm Vol. ${ }^{9} \&$ ', No. $1, r \cdot 1 \cdot$

C- Show improvement after $1 \cdot$ weeks

\begin{tabular}{|l|l|l|l|l|}
\cline { 2 - 5 } \multicolumn{2}{c|}{ Group A } & \multicolumn{2}{l|}{ Group B } \\
\hline Improvement & No. & $\%$ & No. & $\%$ \\
\hline$+\mathrm{Ve}$ & 10 & 1. & $1 \leq$ & $9 \mathrm{r} . \mathrm{r}$ \\
\hline$-\mathrm{Ve}$ & & & & \\
\hline Total & 10 & 1. & 10 & 1. \\
\hline
\end{tabular}

$P=1$ by Fisher exact test

Table 0 : Laboratory investigations in 10. patients

\begin{tabular}{|c|c|c|}
\hline Variable & Total & $\%$ \\
\hline \multicolumn{3}{|l|}{ WBCs count } \\
\hline$<\varepsilon \ldots$ & - & - \\
\hline$\varepsilon \cdots-11 \cdots$ & 11. & MTRT \\
\hline$>11 \ldots$ & $\varepsilon$ & 97.77 \\
\hline Total & 10. & $1 \cdots$ \\
\hline $\begin{array}{l}\text { ESR } \\
<r \cdot \mathrm{mm} / \mathrm{h}\end{array}$ & 7. & $\varepsilon$. \\
\hline$r \cdot-\varepsilon \cdot m m / h$ & $\Lambda$. & or. \\
\hline$>\varepsilon$. & 1. & 7.7 \\
\hline & 10. & $1 \ldots$ \\
\hline
\end{tabular}


were not specific, it is usually normal and moderately raised in brucellosis, and the same findings in this study were obtained.'

Mild raised BAT titer $(1 / 17$.) were found in most cases $(\leqslant \tau . \tau)$, and $(\varepsilon \cdot \%)$ has $1 / \mu r$. while ( $1 r . r \%)$ of cases has $1 / 7 \varepsilon$. titer, these results are in agreement with other study.'

Although brucellosis in humans often diagnosed without the isolation of a casual organism, laboratory investigation of aspirated fluid and tissue specimens obtained at biopsy aided in identification of the disease, and a study done in south Jordan, showed that brucella agglutination test and titer in association with a suggestive clinical picture was more sensitive than blood culture in the diagnosis of brucellosis. ${ }^{19}$ In addition the analysis of synovial fluid in brucellosis demonstrates mononuclear cell predominance with the isolation of the organism in $0 . \%$ of patients.

All the aspirated samples are not suppurative, contain inflammatory fluid with no pus and while B.suis which cause the disease in pigs has higher tendency to suppurative complications, ${ }^{r}$ the surgical drainage needed if the abscess collection found, ${ }^{\text {r }}$ which is usual result of B suis species in pigs which is unusual in our country.

All the included patients were subjected to combined anti brucella antibiotics ,small number got complete cure after 7 weeks, while the large number cured after $\wedge$ weeks and few needed ir weeks. There were no significant difference between those patients who subjected to serial aspiration of synovial fluid and those who did not in the duration of treatment. This is in agreement with fact that no local maneuvers (include serial synovial aspiration of peripheral joint) was needed in brucellosis of peripheral joints. ${ }^{r r}$

Synovial fluid which was aspirated from the affected knee joints; showed inflammatory fluid without pus, not like septic arthritis in which serial fluid aspiration is advised until complete recovery is achieved.

In conclusion, Brucella knee Arthritis is common in Erbil. Aspiration of synovial fluid may help in the diagnosis rather than a treatment of brucella arthritis.

\section{References}

1. Young EJ. Brucella Species. In principle and practice of infectious diseases. (eds G.L. Mandell, J.E. Bennett, and R. Dolin) 1990, pp.r.or-7. Churchill Livingstone, New York.

r. LA Gauri $Q$ Fatima Indian Journal of Rheumatology. Volume I $\leqslant$, No. ', r.. 7; pp. 17-11

r. Gotuzzo E, Alarcon GS, Bocanegra TS, Carrillo C, et al. Articular involvement in human brucellosis: a retrospective analysis of $r . \varepsilon$ cases. Semin Arthritis Rheum 19Ar; $1 r: r \leqslant 0 \_00$.

ะ. Alarcon GS, Bocaneqra TS, Cotuzzo E the arthritis of brucellosis: perspective one handred years after Brucella

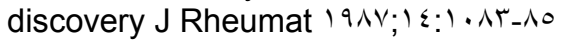

- Mudkour MM. Bone and joint brucellosis.Cambridge univ. Press $1919: 9 \cdot-1 \cdot \leq$.

7. Louie JS, Bocanegra TS. Infectionrelated rheumatic disease: infection: Mycobacterial, Brucella, fungal and parasitic arthritis. In: Rheumatology, rrd edn. Mosby, r...r; $1 \cdot \lambda-r$.

v. Matar G, Khneisser IA, Abdelnoor AM. Rapid Laboratory; confirmation of human brucellosis by P.C.R analysis of atarqet Sequence on $\mathrm{T}$-Kilodalton Brucella antigens DNA. J Clin Microbiol 1997; rะ: $₹ \vee \vee-\varepsilon \vee \wedge$.

^. Gotuzzo E, seas C, Guerra JG, Bocanegra TS, Calvo A. Brucellar arthritis: a study of $r q$ Peruvian families. Ann Rheum Dis 19^v; $₹ 7: 0.7 \_$ 9.

१. Henk L, Kadri SM. Brucellosis. Indian Journal for the Practising Doctor $Y_{.} . \varepsilon$; $1: 11-14$.

1. Saltoglu N, Tasova Y, Inal AS. Efficacy of rifampin plus doxycline versus rifampin plus quinolone in the treatment of brucellosis. Saud Med J r...r;rr:qrl-s.

11. Young Eg. Serologic diagnosis of human brucellosis: analysis of $Y_{1}$ s cases by agglutination test and review of literature Rev. Infec. Dis. $1991 ; 1 \% \wedge$ : roq_VY.

IY-.Baxter MP, Dulberg C, Growing pains in childhood proposal for treatment.J

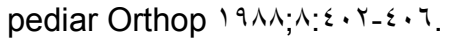

1r. AL-Saaty NY; Clinical presentation of brucellosis in Mosul. Ann Coll Med Mosul, 199r;11: 0-1. 
1 . Gonzalez - Gay- MA; Carcia - PorruaC; Ibanez -D; Garcia - Pais MJ. Osteoarticular complication of brucellosis in anatlantic area of Spain J. Rheumatol. 1999 Jan; Yr(1): $1 \leqslant 1-0$.

10. Ariza J, Pujol M Brucellar Sacroilitis finding in ir episodes clin Infec Dis 199\%; $17: \vee 71-0 .$.

17. Berrocal,A, Gotuzzo,sternoclaviculer brucellar Arthritis as a report of $\mathrm{V}$ cases and review of literature.Journal of Rheumatology, $r \cdot ; 11 \wedge \varepsilon-\wedge \uparrow$

IV. P fischner WCE, Ishak Kg, Nptune E Metal Brucellosis in Egypt, Areview of experience with $r \wedge \wedge$ patients. AM J Med 190V;rr:910-19.

1^. Al Rawi ZS, Al- Khateeb N, Khalifa SJ. Brucella arthritis among Iraqi patients. $\mathrm{Br} \mathrm{J}$ Rheumatol $19 \wedge v ; r \tau: r \leqslant-v$.

19. Issa H, Jamal M. Brucellosis in children in south Jordan. Eastern
Mediterranean Health Journal 1999; $0: 190-9 . r$.

r. Colmenero JD, Reguera JM, Martos F: Complication associated with Brucella mellitensis infection: Study of or. cases .Medicine 1997; V0:190-Y11. Y) - Smith, L.D.and Ficht, T.A. Pathogenesis of brucella. Critical Reviews in Microbiology $999 \cdot ; / \vee, r \cdot 9$. r.

rr. Robert A. Salata, in Goldman-L; Beanett JC. Cecil textbook of Medicine rist edition W.B. Sanders Company, $Y . . ;$; $\left.7 \vee \Lambda_{-}\right) \uparrow \wedge \cdot$.

rr. Pascual E. Brucellar arthritis in: Maddison PJ, Iseberg DA, Woop, Glass DN (eds). Oxford Textbook of Rheumatology, rnd ed. Oxford univ. Press Oxford, 1991:9rV-so. 